Arch. Dis. Childh., 1965, 40, 687.

\title{
LARYNGEAL STRIDOR AND RESPIRATORY OBSTRUCTION ASSOCIATED WITH MENINGOMYELOCELE
}

\author{
BY \\ J. S. FITZSIMMONS* \\ From the Royal Aberdeen Hospital for Sick Children
}

(RECEIVED FOR PUBLICATION MARCH 11, 1965)

Laryngeal stridor in infancy may be associated with a variety of disorders including abnormalities of the nervous system. The association of stridor with meningomyelocele, however, has received only scant attention in published reports, and in view of this the following cases may be of interest.

\section{Case Reports}

Case 1. A male infant, birth weight $6 \mathrm{lb}$. $6 \mathrm{oz}$. $(2,891$ g.), had a lumbar meningomyelocele which was repaired on the second day of life. At the age of 10 days, the infant's anterior fontanelle was tense and an air ventriculogram showed some dilatation of the lateral ventricles. However, subsequent head growth was not excessive, and by 5 months the skull circumference was $17 \frac{3}{8}$ in. $(44 \mathrm{~cm}$.). At the age of 2 months the child developed laryngeal stridor which worsened over a period of one week. Laryngoscopy revealed no local cause for this symptom, but two weeks later tracheostomy was necessary for severe respiratory obstruction. Following operation, there were repeated episodes of vomiting and respiratory infection. It was six months before the infant could manage without the tracheostomy tube. Stridor has not recurred and the infant remains well without evidence of hydrocephalus. The only abnormality is paralytic talipes of the left foot.

Case 2. A male infant, birth weight $6 \mathrm{lb} .7 \mathrm{oz}$. $(2,919$ g.), had a lumbar meningomyelocele which was repaired on the first day of life. Hydrocephalus subsequently developed and a Spitz-Holter valve was inserted when the patient was 6 weeks old. From birth he showed a flaccid paraplegia of both lower limbs and double sphincter paralysis.

Laryngeal stridor and difficulty in swallowing were noticed when he was 4 months old, and he was admitted to hospital at the age of 5 months with increasing respiratory obstructicn. Laryngoscopy revealed bilateral adductor spasm of the vocal cords and urgent tracheostomy was necessary. The tracheostomy tuke had to be maintained in position for six months, though frequent attempts to remove it were made. The severe difficulty

\footnotetext{
* Present address: Mansfield and District General Hospital, West Hill Drive, Mansfield, Notts.
}

in swallowing persisted during this period and the patient had to be tube-fed for several weeks. Now, at the age of 2 years, he has only slight stridor after crying but he still has difficulty in swallowing solids. There have been no further episodes of respiratory obstruction.

Case 3. A male infant, birth weight $5 \mathrm{lb} .8 \mathrm{oz}$. $(2,494$ g.), had a lumbar meningomyelocele which was repaired within 24 hours of birth. Following operation, transient cyanotic attacks occurred without obvious cause, and at the age of 5 weeks he developed laryngeal stridor. This was never very severe, but at this time he had an attack of pneumonia which responded to antibiotics. Hydrocephalus developed and a Spitz-Holter valve was inserted at 7 weeks of age. At operation, inspection of the larynx revealed no local lesion. Now, at the age of 6 months, the infant is well and the head circumference is $16 \frac{3}{4}$ in. $(42 \cdot 5 \mathrm{~cm}$.). There is still obvious, but variable, stridor. Except for the period when he had pneumonia, this child did not have significant respiratory distress.

\section{Discussion}

The cause of laryngeal stridor in these patients is uncertain. Examination of the larynx revealed no local lesion, but the presence of congenital abnormalities of the nervous system suggested the possibility of faulty nervous control of the vocal cords. Graham (1963) reported two cases of bilateral vocal cord paralysis associated with meningomyelocele and suggested that the stridor resulted from traction on the vagus nerve. Both his cases required tracheostomy for respiratory obstruction and both died: at necropsy they were found to have the Arnold-Chiari malformation with caudal displacement of the brainstem. Smith (1959) reported two cases of stridor with meningomyelocele, and at necropsy on $€$ of these infants had hydrocephalus without the ArnoldChiari malformation. He suggested that 'coning' of the medulla might cause disordered vagal action and, hence, stridor. In our Case 3, the possibility of 'coning' was considered. This infant's stridor was thought to be most marked when the anterior fontanelle was very tense. However, removal of 
cerebrospinal fluid from the lateral ventricles produced no dramatic change and the stridor persisted after the insertion of a Spitz-Holter valve.

Kiger, Kohlmoos, and May (1964) described an infant with bilateral vocal cord paralysis and an occipital meningomyelocele. Stridor developed at the age of 9 days and the infant required tracheostomy for respiratory obstruction at 6 months. The child still had the tracheostomy tube in position at the age of $2 \frac{1}{2}$ years; there was no evidence of hydrocephalus. The authors mentioned Graham's cases and also discussed the Arnold-Chiari malformation as a cause of the vocal cord paralysis.

In a survey of 80 infants with stridor, Apley (1953) reported 2 with associated meningomyelocele. They had persistent stridulous breathing and opisthotonus. Necropsy revealed no obvious cause for the respiratory symptoms and there was no mention of the Arnold-Chiari malformation. It was suggested that the stridor resulted from central nervous system dysfunction. Approximately half of these 80 infants had frequent choking attacks and difficulty with swallowing. This is of interest in view of the marked feeding difficulty encountered in Case 1. There was no obvious cause for this additional complication, but it suggested the possibility of brain-stem involvement. Bigler, Holinger, Johnston, and Schiller (1954), reporting respiratory obstruction with meningomyelocele, mentioned that their two patients had associated cranial nerve abnormalities. They did not, however, elaborate on these other lesions.

In Apley's series, 16 infants had mental retardation, and the association of stridor with low intelligence has been confirmed by Benians, Benson, Sherwood, and Spector (1964).
Graham (1963) commented on how seldom stridor has been reported in association with meningomyelocele and hydrocephalus, despite the frequency of these congenital malformations. However, the association may be commoner than the literature suggests, but unless the respiratory symptoms were severe they would be overshadowed by the other lesions. In Case 3 the stridor caused some concern, but in the other two patients the respiratory symptoms were of major importance and required urgent surgical treatment.

\section{Summary}

Three cases of laryngeal stridor associated with meningomyelocele are reported. Two required tracheostomy for respiratory obstruction and both recovered. The mechanism of production of the stridor is discussed.

I am grateful to Professor R. G. Mitchell and Dr. N. S. Clark for their help and advice in the preparation of this paper.

\section{REFERENCES}

Apley, J. (1953). The infant with stridor: a follow-up survey of 80 cases. Arch. Dis. Childh., 28, 423.

Benians, R. C., Benson, P. F., Sherwood, T., and Spector, R. G. (1964) Intellectual impairment in congenital laryngeal stridor. Guy's Hosp. Rep., 113, 360.

Bigler, J. A., Holinger, P. H., Johnston, K. C., and Schiller, F. (1954). Tracheostomy in infancy. Pediatrics, 13, 476.

Graham, M. D. (1963). Bilateral vocal cord paralysis associated with meningomyelocele and the Arnold-Chiari malformation. Laryngoscope (St. Louis), 73, 85.

Kiger, J. R., Kohlmoos, H. W., and May, I. A. (1964). Bilateral vocal cord paralysis in infancy. Amer. J. Dis. Child., 108, 648.

Smith, M. E. N. (1959). The association of laryngeal stridor with meningo-myelocele. J. Laryng., 73, 188. 